\title{
MEDICATION ERRORS IN NEONATES ADMITTED IN INTENSIVE CARE UNIT AND EMERGENCY DEPARTMENT
}

\author{
SUKSHAM JAIN, SRIKANTA BASU1, VEENA R. PARMAR
}

\section{ABSTRACT}

BACKGROUND: Medication is the most common health-care intervention, and the errors arising out of its usage are potentially an avoidable cause of iatrogenic injuries. There are reports of medication errors from neonatal emergency setups. AIMS: To study the medication errors of ordering, dispensing and administering in neonates admitted for emergency care and to compare the errors occurring in the emergency department (ED) with those occurring in the neonatal intensive care unit (NICU) of a teaching hospital in north India. Primary objective: To study the medication errors in ordering and dispensing for neonates. Secondary objective: To compare these errors in 2 different settings - ED and NICU. MATERIALS AND METHODS: We did a retrospective chart review of neonatal prescriptions written in the 4 months from January to April 2004 in the neonatal intensive care unit and the pediatric emergency department. The prescriptions were analyzed from the case records bearing an even registration number, obtained from the hospital 'medical records' section. Medication error was defined as 'any preventable event that occurs in the process of ordering, transcribing, dispensing, administering or monitoring a drug irrespective of whether the injury occurred or potential for injury was present.' RESULTS: A total of 821 prescriptions were analyzed and 81 (9.6\%) errors were detected. The error rate was found to be $1.5(54 / 38)$ and $0.7(27 / 38)$ per patient in ED and NICU, respectively, being highly significant in ED. Every tenth prescription had medication error in ordering or dispensing; of this, every sixth prescription in ED and nineteenth prescription in NICU had medication error. Dosing errors were the commonest form of detected errors. None of the errors caused any significant harm to the patient but had the potential to cause severe injury, and majority of these errors were preventable. CONCLUSION: Medication errors are common in neonatology; more so, in emergency departments than in the neonatal intensive care units.

Key words: Emergency department, intensive care, medication errors, neonates DOI: $10.4103 / 0019-5359.50763$

Department of Pediatrics, Government Medical College and Hospital, Chandigarh, 'Kalawati Saran Children's Hospital, Lady Hardinge Medical College, New Delhi, India

Correspondence:

Dr. Suksham Jain,

Department of Pediatrics, Government Medical College and

Hospital, Sector 32 B, Chandigarh - 160 030, India

E-mail: dr.sukshamj@gmail.com

\section{INTRODUCTION}

'Medical errors' is a general term used to denote all errors that occur within the healthcare system, e.g., diagnostic errors, equipment failure, mishandled surgery and medication errors. Of these, medication errors can cause 
significant problems for physicians and patients and may result in serious patient morbidity and mortality, increased health-care costs and, in some cases, loss of confidence in the health-care system. ${ }^{[1,2]}$ In a report by Leaser et al., it was reported that medication errors occur in 3.99 per 1000 medication orders for hospital patients. About $9 \%$ of these occurred in children; and $5 \%$, in the emergency department. Of these iatrogenic injuries, $6 \%$ were potentially fatal, $14 \%$ were potentially serious and $80 \%$ were potentially significant; and notably, many of these errors were preventable. ${ }^{[3]}$

'Neonates' is a vulnerable group for dosing and dispensing errors because neonates have a rapidly changing body surface area and weight; a rapidly developing system of drug absorption, metabolism and excretion; an inability to communicate with the provider; and off-label or unlicensed drug usage. Most of the drugs used in neonates are available in dosages and units ready for dispensing in children or adults. This needs a lot of calculation and has a potential for errors. Further, emergency department has a high volume and acuity of work, more stress and noise, less time available per patient and dissimilar patients. There is no systematic review available on medical errors in neonatology. Error reports vary widely in different studies because of the difference in definition and method used for detecting errors. ${ }^{[3-15]}$ Medication errors in children are reported in literature; but to our knowledge, there are a very few studies that focus on medication errors in neonatology but none from India. In this pilot study, which was a retrospective chart review, we analyzed the medication errors and their potential outcome in the neonatal prescription ordering and dispensing, which was the primary objective; and further, we compared such errors occurring in the emergency department (ED) with those occurring in the neonatal intensive care unit (NICU).

\section{MATERIALS AND METHODS}

We conducted a chart review of neonates who were treated in the emergency ward (ED-group I) and neonatal intensive care unit (NICUgroup II) of our hospital. Pediatric emergency department has 10 beds and provides services to pediatric patients of all age groups, whereas NICU is 6-bedded and provides services to intramural neonates only. Doctor-patient ratio was 1:10 in ED and1:6 in NICU. Emergency round was taken usually by 2 pediatricians, and intensive care was supervised by 1 pediatrician round the clock. Once a week, a grand round was undertaken in both the areas. In case of discrepancy of opinion in a patient's diagnosis or management, a round-table discussion of the case was done as per the routine working of the department. Prescription writing was done mainly by the pediatric residents (who had completed their postgraduate studies or had undergone at least 2 years of training in pediatrics). All the orders were handwritten. As a routine practice in emergency department and NICU, date and time of prescription and of dispensing was recorded. Dispensing and administering of drug were done by staff nurses and countersigned. Staff nurse-patient ratio was $1: 6$ or $1: 7$ in ED and 1:3 in NICU. Both the areas had one sister in charge. There was no change in policy during this period. Convenience sampling was done, and 38 case records bearing an even registration number 
were picked up from each setting (ED and $\mathrm{NICU}$ ) over the 4-month period from January to April 2004. Only those neonates who had a hospital stay of more than 48 hours were included in this study. The neonates who died, transferred out of the ED or NICU in less than 48 hours, left the hospital against medical advice, or had major congenital malformations were not included in the study. The details of all the case records were entered by a dataentry clerk and sent to the medical records section of the hospital within 24 hours of the discharge or death, as a matter of hospital policy. Every record was retained in this section after dual entry and was retrieved only with written permission of the head of the concerned department. The data was analyzed by a doctor who was not posted in both these areas during the study period. The entire database was further reviewed by a senior investigator. Drug doses were verified from the drug formulary followed in the department.

Medication error was defined as 'any preventable event that occurs in the process of ordering, transcribing, dispensing, administering or monitoring a drug irrespective of whether the injury occurred or potential for injury was present.' Adverse event was considered to have occurred if it occurred as a result of medical management, rather than the disease process, and resulted in prolonged hospital stay or disability at discharge. The event was considered to be serious if it resulted in mortality; and preventable, if it could be avoided as per the evidence available and current knowledge.

The severity levels of errors were graded as per the criteria provided by The American Society of Hospital Pharmacists. Level I, no injury; level II, increased clinical monitoring (no harm); level III, increased laboratory monitoring (no harm); level IV, required another drug/ prolonged stay; level $\mathrm{V}$, permanent harm; level VI, mortality [Figure 1]. The permission of the institute's ethical committee was taken before commencing the study.

Statistical analysis was done using SSPS 13.0 software. Chi-square test (unpaired $t$

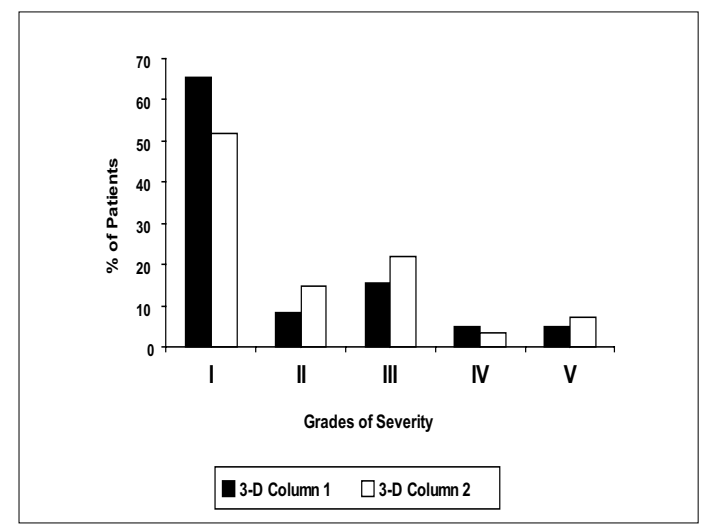

Figure 1: Grades of severity

\section{Types of errors were classified as follows:}

\begin{tabular}{ll}
\hline $\begin{array}{l}\text { Wrong dose } \\
\text { Wrong time }\end{array}$ & $\begin{array}{l}\text { Unexplained deviation of more than 10\% of normal - over/under the ordered dose } \\
\text { More than } 30 \text { minutes for emergency medicine }\end{array}$ \\
Wrong rate & $\begin{array}{l}\text { Drug delivered slower or faster than the prescribed. 24-hour volume of fluid more than 10\% of } \\
\text { over/under the ordered rate; or hourly rate more than } 50 \% \text { over/under the ordered rate. }\end{array}$ \\
Wrong preparation technique & $\begin{array}{l}\text { Incorrect dilution with correct drug dosage, mixing of incompatible drugs } \\
\text { Route other than the prescribed for the use in neonates }\end{array}$ \\
Wrong route & $\begin{array}{l}\text { Incorrect method of administration, e.g.. intravenous instead of intramuscular or arterial } \\
\text { Wrong administering technique }\end{array}$ \\
Omission & Failure to administer or omission of prescribed dose/drug type \\
Others & Drug not authorized, wrong site, wrong patients, etc.
\end{tabular}


test) was applied and a $P$ value of $<0.05$ was considered to be significant; and $<0.001$, as highly significant.

\section{RESULTS}

A total of 821 prescriptions were analyzed and 81 errors were detected. Three hundred twentyseven prescriptions in ED (group I) and 494 prescriptions in NICU (group II) were written during the study period. Medication errors were detected in $81(9.6 \%)$ of these $(16.7 \%$ in ED and $5.4 \%$ in NICU). Every tenth prescription had medication error in ordering or dispensing; of this, every sixth prescription in ED and nineteenth prescription in NICU had medication error. Mean birth weight was $2.1 \mathrm{~kg}$ and $1.9 \mathrm{~kg}$, and mean gestation age was 35.1 weeks and 34.4 weeks in group I and group II, respectively.

Medication errors were significantly high $(P<0.001)$ in the emergency department, not only as the overall number of errors but also as the number of errors per patient and errors per day [Table 1]. Health personnel were involved in errors related to drug ordering and were mainly resident doctors (senior residents, 70\% [38/54]; and junior residents, 9\% [5/54] in ED and senior residents, 89\% [24/27] in NICU). Staff nurses were involved in dispensing errors $(21 \%$ [11/54] of errors in $\mathrm{ED}$ and $11 \%$ [3/27] of errors in NICU) as per the chart review. Errors were identical during all the shifts of a day, i.e., morning (8:00 a.m.-2:00 p.m.), evening (2:00-8:00 p.m.) and night (8:00 p.m.-8:00 a.m.), in both the areas.

The spectrum of errors is depicted in Table 2. Level I-V errors were $(35,5,8,3,3$ in ED vs. 14, 4, 6, 1, 2) in NICU. Level IV errors errors that had a potential to cause harm to the patient or another drug was required or the patient's stay in the hospital was prolonged were detected in $9(11 \%)$ patients. None of the errors was severe enough to cause mortality or permanent damage during hospital stay. The remaining 72 (89\%) errors were mild and

Table 1: Medication errors in the two groups

\begin{tabular}{lccc}
\hline Medication Error & $\begin{array}{c}\text { Group I } \\
\text { Emergency Department }\end{array}$ & $\begin{array}{c}\text { Group II } \\
\text { Neonatal Intensive Care Unit }\end{array}$ & $P$ value \\
\hline Total prescription & 327 & 494 & 13 \\
Prescription per patient & 8.6 & 302 & \\
Total days of intensive care & 95 & 27 & $* 0.001$ \\
Total error & 54 & 0.7 & $* 0.001$ \\
Errors per patient & 1.5 & 0.09 & $* 0.001$ \\
Errors per day & 0.6 & &
\end{tabular}

Table 2: Types of errors* in emergency department and neonatal intensive care unit

\begin{tabular}{lcc}
\hline Type of Errors (overall \%) & $\begin{array}{c}\text { Group I }(\mathrm{N}=54) \\
\text { Emergency Department }\end{array}$ & $\begin{array}{c}\text { Group II }(\mathrm{N}=27) \\
\text { Neonatal Intensive Care Unit }\end{array}$ \\
\hline Wrong dose (42) & $21(38)$ & $13(48)$ \\
W Wrong time (4.9) & $4(6.9)$ & - \\
Wrong rate (9.8) & $4(6.9)$ & $4(14.8)$ \\
W Wrong technique of preparation (4.9) & $3(5.2)$ & $1(3.7)$ \\
Wrong route (6) & $5(8.6)$ & -- \\
Wrong administering technique (12) & $6(10.4)$ & $4(14.8)$ \\
Omission (11) & $7(12)$ & $2(7)$ \\
Others (8.6) & $4(6.9)$ & $3(11)$ \\
\hline
\end{tabular}

${ }^{*}$ Errors classified as per American Society of Hospital Pharmacists ${ }^{[1]}$, Figures in parentheses are in percentage 
caused no harm to the patient (types I, II and III), Figure 1 of these cases.

\section{DISCUSSION}

Pediatric medication errors are different from those occurring in adults because doses are individually based on weight, age and body surface area. More errors occur in the pediatrics department, and that too, more so in the intensive care unit. ${ }^{[4,5]}$ Overall incidence of errors was $9.6 \%$ (17.7\% in ED, $5.4 \%$ in $\mathrm{NICU})$, which is similar to that reported in other studies in literature. ${ }^{[3-7]}$

Error rates as overall incidence per patient and per-day incidence were significantly high in the emergency department. We observed an error rate of $17 / 100$ orders in ED and 8/100 orders in $\mathrm{NICU}$, which is similar to the error rate of $5.7 / 100$ to $24 / 100$ orders reported in other studies. ${ }^{[8,9]}$ The probable causes of high error rate in the emergency department could be stressful and noisy environment, overcrowding of patients and their caregivers, verbal orders being given often and less manpower. Many studies have reported more errors in evening and night shifts, ${ }^{[6-8]}$ whereas one study has reported more errors in day shift. ${ }^{[6]}$ In our study, no variation in errors with regard to shifts was noted.

Medication errors may occur at any step in the process from ordering to transcription, dispensation and administration. Ordering by the prescriber is the most error-prone step in the medication process. Most common errors of medication are dose related, especially in pediatric population, and these may vary from $14 \%$ to $82 \% .^{[5,6]}$

Most common errors identified were related to antibiotics dose, intravenous medication dilution, electrolytes and fluid administration and bronchodilators for nebulization. Dosing errors (44\%) were the leading cause of mishaps in our study too. In one case, the error was due to a misplaced decimal point, and this resulted in a 10-fold increase in delivery of morphine to a ventilated newborn. Fortunately, no permanent damage was observed in the baby. It has been noted in other studies that propensity to commit a 10 -fold error is very high in neonatal prescription. ${ }^{[10]}$ It is suggested that the physician writing the medication orders always place a zero before a decimal point to express a number less than one (such as 0.5 $\mathrm{mL}$ ) but never use a terminal zero (such as in 5.0), since failure to see the decimal point may result in the patient getting 10 times the appropriate dose.

In this study, the other group of drugs which were prescribed lower or higher than the recommended dose was 'antibiotics'. The reported incidence of 'antibiotics prescription' error in literature is between $30 \%$ and $44 \%{ }^{[4,5,8]}$ Moreover, there were 3 instances where the doses of nephrotoxic antibiotics like cephalosporins and aminoglycosides were modified very late in the course in neonates with renal failure, as it could be correlated from the date of renal function test and change in dose of antibiotic in the prescription chart. The doses of antibiotics were quite often not modified as per weight and maturity, especially in neonates less than 7 days old. The fluid used for correcting hypernatremic dehydration did not have correct amount of sodium and was inadequate. Two neonates with hypoglycemia were getting inappropriate concentration of glucose; a similar finding was noted by 
others. ${ }^{[5]}$ The reported incidence of errors of omission in literature is up to $12 \%,,^{[4,7]}$ and ionotropes are most commonly implicated. In our study, ionotropes were started late in the course or were omitted late, as was correlated from flow sheet of patient-monitoring and time of change in prescription order. In 1 newborn, potassium chloride was omitted so late that it resulted in hyperkalemia. Sodium bicarbonate was diluted with sodium chloride solution instead of the recommended diluents. Nebulization error is reported in up to $11 \%$ by Kozer et al..9]; and in our study, the dose of nebulization solution was rarely mentioned. Both experienced and inexperienced staff can make medication errors. In our setup, nurses are mainly involved in dispensing medication, so we could pick up only documented dispensing errors, which were $16 \%$; and expectedly, this figure was much lower than that in other studies, where it ranged from $35 \%$ to $60 \% .^{[5,6]}$ Apart from dose-related errors, other types of errors reported in literature are wrong rate, $13.7 \%$ to $43.2 \%$; wrong time, $21.6 \%$; wrong route, $2.6 \%$ to $4.1 \%$; wrong drug, $1.8 \%$ to $13.3 \%$; wrong technique, $13 \%$ to $14 \%$; and omission, up to $12 \% .{ }^{[5,7]}$ Incidence of these errors found in this study, was comparable to that found in literature.

This study had certain limitations. Firstly, there was no incident-reporting. Secondly, the study design was 'retrospective chart review.' This system was developed by Brennan et al. ${ }^{[15]}$ It has a bias of error type, difficulty in ascertaining and correlating the cause and effect phenomenon, and inconsistency in use of definition of errors. ${ }^{[12]}$ There is no systematic review on medication error detection. Chart reviews are better at detecting errors in ordering than the incident-reporting but poorer than direct observation method for detecting errors of administration. Errors in ordering of $157 / 1000$ patient day were picked up by chart review $^{[8]}$ as compared to $13.4 / 1000^{[13]}$ patient day by incident-reporting method, and dispensing errors of $30 \%{ }^{[6]}$ could be detected by direct observation as compared to $4 \%^{[8]}$ by chart review. Retrospective chart review method can become more sensitive and the most promising method of error detection if it is 'trigger based.' This study detected 0.7 error/patient in NICU and double this rate in ED. In a trigger-based method, there is only 1 study available, and it has detected 0.74 error/ patient. ${ }^{[14]}$ Prospective studies have shown more difference in error reporting, viz., $14.7 \%$ to $46 \%$ error rate per NICU admission, ${ }^{[5,8]}$ as compared to that in retrospective studies, where it varied from $0.98 \%$ to $10.1 \%$ of admissions. ${ }^{[4,9]}$ latrogenic event rate per patient of as high as 1.9/patient in NICU was found in a prospective study, ${ }^{[15]}$ but this study included not only drug errors but also errors which were secondary to central catheters, nosocomial, cutaneous, ventilation-related, etc. Thirdly, because of small size of prescriptions in the sample of this study, serious adverse events could not be detected. Fourthly, data was not retrieved by true randomization. Only potential to cause harm was noted and analyzed, which was not trigger based or on a Likert scale; so bias in reporting the cause-effect relationship could exist. However, to decrease this bias, the entire data was analyzed by another expert and both the experts were not involved in patient management during the study period.

This study was an effort to sensitize health-care personnel to the importance of medication errors. Results of the study are quite similar to the study 
that used trigger-based method, which is a good and more sensitive screening tool for medication errors.

Ordering errors can be picked up in a more sensitive way by trigger-based methods. A prospective study with pharmacy involvement can pick up more dispensing errors than retrospection because of under-reporting. Majority of these errors are preventable if doctors and sisters consult the drug formulary more often and doses and related issues are routinely cross-checked during the clinical rounds.

Moreover, working environment of medical and paramedical staff (duty hours, shift of the duty, replacement, training, etc.) should be addressed so as to minimize these errors.

\section{REFERENCES}

1. American Society of Hospital Pharmacists. ASHP guidelines on preventing medication errors in hospitals. Am J Hosp Pharm 1993;50:305-14.

2. Bates DW, Spell N, Cullen DJ, Burdick E, Laird N, Petersen LA, et al. The costs of adverse drug events in hospitalized patients. JAMA 1997;277:307-12.

3. Lesar TS, Briceland L, Stein DS. Factors related to errors in medical prescribing. JAMA 1997;277: 312-7.

4. Ross LM, Wallace J, Paton JY. Medication errors in a pediatric teaching hospital in the UK: Five years operational experience. Arch Dis Child 2000;83: 492-7.

5. Raju TN, Kecskes S, Thornton JP, Perry M, Feldman S. Medication errors in neonatal and paediatric intensive-care units. Lancet 1989;2:374-6.

6. Selbst SM, Fein JA, Osterhoudt K, Ho W. Medication errors in pediatric emergency department. Pediatr Emerg Care1999;15:1-4.

7. Kozer E, Scolnik D, Macpherson A, Keays T, Shi K, Luk $\mathrm{T}$, et al. Variables associated with medication errors in pediatric emergency medicine. Pediatrics 2002;110:737-42.

8. Kaushal R, Bates DW, Landrigan C, McKenna KJ, Clapp MD, Federico F, et al. Medication errors and adverse drug events in pediatric inpatients. JAMA 2001;285:2114-20.

9. Cimino MA, Kirschbaum MS, Brodsky L, Shaha $\mathrm{SH}$. Child Health Accountability Initiative: Assessing medication prescribing errors in pediatric intensive care units. Pediatr Crit Care Med 2004;5:124-32.

10. Koren G, Barzilay Z, Greenwald M. Tenfold error in administration of drug doses: A neglected iatrogenic disease in Pediatrics. Pediatrics 1986;77:848-9.

11. Brennan TA, Leape LL, Laird NM, Hebert L, Localio AR, Lawthers AG, et al. Incidence of adverse events and negligence in hospitalized patients: Results of the Harvard Medical Practice Study I. N Engl J Med 1991;324:370-6.

12. Stavroudis TA, Miller MR, Lehmann CU. Medication errors in neonates. Clin Perinatol 2008;35:141-60.

13. Walsh KE, Kaushal R, Chessare JB. How to avoid pediatric mediaction errors: A user's guide to the literature. Arch Dis Child 2005;90:698-702.

14. Sharek PJ, Horbar JD, Mason W, Bisarya H, Thurm CW, Suresh G, et al. Adverse events in the neonatal intensive care unit: Development, testing, and findings of an NICU-focused trigger tool to identify harm in North American NICUs. Pediatrics 2006;118:1332-40.

15. Ligi I, Arnaud F, Jouve E, Tardieu S, Sambuc R, Simeoni U. latrogenic events in admitted neonates: A prospective cohort study. Lancet 2008;371: 404-10.

Source of Support: Nil, Conflict of Interest: None declared. 